\title{
Disadvantage, Risk and the Social Determinants of Health
}

\author{
Jonathan Wolff*, Centre for Philosophy, Justice and Health, University College \\ London
}

*Corresponding author: Department of Philosophy, University College London, Gower Street, London, WC1E 6BT, UK. Telephone: 020-7679-3067; Fax: 202-7679-3336; Email j.wolff@ucl.ac.uk.

The paper describes a project in which the thesis of the social determinants of health is used in order to help identify groups that will be among the least advantaged members of society, when disadvantage is understood in terms of lack of genuine opportunity for secure functioning. The analysis is derived from the author's work with Avner de-Shalit in Disadvantage (Oxford University Press, 2007).

\section{Introduction}

The thesis of the social determinants of health is beginning to have a striking impact in political philosophy, in several ways. For example, it has reignited interest in the issue of income inequality. Many political philosophers seem to have been convinced by arguments from Rawls (1971), Parfit (1998) or Frankfurt (1987) that what matters is not equality but giving priority to the worst off, or, alternatively, ensuring that everyone reaches a decent level of sufficiency. On such views there is nothing wrong with inequality, provided it also advances the interests of the worst off, or at least does not threaten their sufficiency. Yet learning that income inequalities correlate with poorer health and life expectancy not only for the worst off, but arguably for all, can threaten the comforting thought that all might benefit from the incentives to productivity thought to be provided by allowing income inequalities (see, for example, Wilkinson, 1996; Marmot, 2004). The picture now appears much more complex, and a range of factors need to be taken into account (Barry, 2005; Daniels, 2008). Hence the normative implications of the social determinants of health need to be thought through in detail, and that work is now ongoing.

In this paper, however, I want to describe a different connection between the theory of the social determinants of health and a project in political philosophy. In this instance the object of study is not the normative consequences or analysis of the social determinants of health, but how the social determinants of health, as an empirical hypothesis, can support a project in political philosophy. Specifically what I shall do is describe the use that has been made of research into the social determinants of health in the analysis of disadvantage set out in Wolff and de-Shalit (2007). I will also conclude by considering what further research will be needed before it will be reasonable to formulate policy recommendations.

\section{The Project and Its Central Problem}

The analysis of disadvantage referred to above is part of a project to combine a theoretical discussion on the nature and importance of equality, broadly conceived, in political philosophy with more empirically grounded policy analysis. Hence, to re-cycle an overused phrase, our purpose was to connect theory and practice. This in turn gives rise to two constraints on the use of political philosophy as part of this particular project (which is not to say that all uses of political philosophy must obey the same constraints). First, it is important to distinguish those disputes in the particular subject area that may have important policy implications in the short to medium term, and those that either will only have implications in the much longer term, or perhaps only at a theoretical level. So, to take our main example, theories of equality, priority and sufficiency, as introduced above, provide different accounts of the nature of a just society. However, they agree in at least one important respect with regard to immediate policy: that it is extremely important to be able to identify the worst off, and for governments to take steps so that the lives of the least advantaged are improved. Indeed, such a concern with improving the lives of the most disadvantaged can even be regarded as a consensus point among many theories, including some at the more conservative end of the spectrum. There are many questions of detail that remain, but some of the most important questions of principle can be suspended, at least for the time being. 
In effect, then, the first constraint on the project is to fight only those battles that need to be fought. The second is rather different. As they stand, many theories in political philosophy are not easy to connect with public policy. Consider, for example, the theory of equality of welfare (or equality of opportunity for welfare), where welfare is to be thought of in terms of preference satisfaction (Arneson, 1989). If this were to be implemented then it appears that social policies need to be assessed in terms of how they affect the satisfaction of individual preferences. Even if we put aside the question of how such data might be captured, we should note that however attractive the proposal seems, it is not how national and local governments operate. For example, families are provided with public housing in an order of priority that is not determined by how well, in general, their preferences are satisfied, or even by how well their current housing satisfies their preferences. Rather such families are typically assessed against certain objective criteria laid down as indicators of housing need, and it would seem very hard to make the case that current public policy should be abandoned and replaced with an approach more consonant with the theory of equality of preference satisfaction. And of course this example is not specific to housing; there are many areas of government policy where policy is aimed at meeting a certain need for people-health, mobility, employment, education-rather than advancing people's preferences or even income, in any generalised way. If political philosophy is to be policy relevant, it needs to explain how its understanding of individual well-being — of advantage or disadvantage — connects with possible social policy, so that it can make assessments of what policies should, or should not, be pursued.

This second constraint may seem perfectly reasonable, but it has the consequence, so it appears, that there are many different ways of being advantaged or disadvantaged, and hence human well-being, as far as public policy is concerned, must be understood in pluralistic terms. At least as far as social policy is concerned, the idea of advantage and disadvantage is complex, having many elements that cannot all be reduced to a single one. While, again, this may seem perfectly reasonable, it dramatically complicates matters for political philosophy and for the project in hand. For a pluralistic understanding of disadvantage appears to undermine the 'consensus' project of identifying the least advantaged and taking steps to ensure that their lives are improved. For who are least advantaged on a pluralist view? Those in the poorest health? Those with the worst housing? Those who are least educated? This apparent tension between proposing that governments have a special obligation to help the least advantaged, and the difficulty of identifying the least advantaged, appears problematic. However, it also appears that empirical work on the social determinants of health helps provide an answer. In fact there are two questions on which it may well assist: first, who are the least advantaged, and second how can their lives be improved? There are, however, some further theoretical elements that need to be put on the table before it can be seen how the pieces fit together.

\section{Understanding Disadvantage}

The suggestion that there are many aspects of advantage and disadvantage was defended in terms of the many differing goals of public policy, meeting needs of various sorts, which could not all be reduced to the same goal, or addressed in the same way. Now it is perfectly possible for a theorist to reject this argument, and to claim that ultimately preference satisfaction or perhaps income can be used as a universal currency of justice, and to argue that the worst off are those with the lowest preference satisfaction or income. It would then be necessary to provide a set of 'bridging principles' to connect such a theory with public policy recommendations, translating public policy initiatives into welfare or income. The approach in Disadvantage, however, is to take the apparent pluralism of disadvantage at face value, but to work out an alternative way of identifying the least advantaged on a pluralistic view.

Having taken that step it seems necessary to provide a more systematic account of disadvantage than these sketchy remarks so far reveal. Within the philosophical literature there are many existing proposals concerning how to understand well-being on a pluralistic basis. (For discussion, see Brock, 1998; Alkire, 2002.) Some of these proposals set out lists of needs, sometimes restricted to an account of basic needs. On such a list it is likely that one will find obvious items such as nutrition, health, housing, education, companionship, security, as well as others that may or may not seem as firmly based. An important aspect of a need is that it appears that the logic of need is always 'person $\mathrm{p}$ needs $\mathrm{x}$ in order to $\mathrm{y}$ '. That is, need is a three-place relation between a person, a needed object or service, and a goal that can be better pursued with the needed object or service. However, if needs are understood in this way, it appears that there is something instrumental, or at least less than ultimate, about needs, for needs are always needs for something. But for what? Presumably for the elements of a flourishing life.

Seeing matters this way may make it appear that it is at least equally important to identify those elements of 
a flourishing life, for otherwise there will be no way of deciding what should be on the list of needs. However, once the account of a flourishing life is set out, there then comes the question of whether the list of needs serves any fundamental purpose. For if the elements of a flourishing life can be achieved without some of the items that are claimed to be needed, then, strictly, they turn out not to be needed after all. Therefore, there appears to be some sort of logical priority to the idea of a flourishing life. Accordingly, then, there appears to be good reason to focus, at least in the first instance, on the elements that make up a flourishing human life.

Within the philosophical literature the leading account of this nature is the analysis of human capabilities provided by Martha Nussbaum (2000), building in part, on the previous work of Amartya Sen $(1980,1992,1997)$. According to Nussbaum, based primarily on philosophical analysis, but also on extensive discussion with empirical researchers and activists, especially in India, the essential human capabilities are these:

1. Life: Being able to live to the end of a human life of normal length.

2. Bodily health: Being able to have good health, including reproductive health; to be adequately nourished, to have adequate shelter.

3. Bodily integrity: Being able to move freely from place to place; being able to be secure against assault, including sexual assault, child sexual abuse, and domestic violence; having opportunities for sexual satisfaction and for choice in matters of reproduction.

4. Sense, imagination, and thought: Being able to imagine, think, and reason - and to do these things in a way informed and cultivated by an adequate education. Freedom of expression, speech, and religion.

5. Emotions: Being able to have attachments to things and people outside ourselves; to love those who love and care for us.

6. Practical Reason: Being able to engage in critical reflection about the planning of one's life.

7. Affiliation: Being able to live with and toward others, to recognize and show concern for other human beings, to engage in various forms of social interaction. Having the social bases of self-respect and non-humiliation. Not being discriminated against on the basis of gender, religion, race, ethnicity, and the like.

8. Other species: Being able to live with concern for and in relation to animals, plants, and the world of nature.

9. Play: Being able to laugh, to play, to enjoy recreational activities.
10. Control over one's environment: Being able to participate effectively in political choices that govern one's life. Being able to have real opportunity to hold property. Having the right to seek employment on an equal basis with others.

Nussbaum, following Sen, makes a distinction between human capabilities and functionings. Functionings are 'beings and doings' as set out in the list above. A capability is the capability to achieve a functioning. It is important, on this view, to acknowledge that it is possible to have a capability to achieve a functioning, yet choose not to do so. Sen provides the famous example of a wealthy individual who has chosen to fast to a degree where they are now undernourished. Nevertheless, although lacking the functioning of nutrition the individual in question does enjoy the capability. He simply has chosen not to convert the capability into a functioning. Nussbaum gives the example of religious observance. It is important, she argues, that everyone has the capability to be religious, but it is just as important to ensure that it is a matter of choice for each individual whether they decide to enjoy the functioning of being religious. That is to say, while it is important to give everyone the opportunity to be religious according to their own convictions, religious freedom requires that no one is forced to follow a religion.

There is, therefore, an important 'space' between capabilities and functionings, at least in the case of some capabilities and functionings. For others it may be unclear how much we want to make of, or value, this space. For example it might be seen as highly problematic if a group in society that is believed to have the capability for health and long life, nevertheless chose to behave in ways that gravely damaged their health and reduced their life expectancy. But I will leave that to one side.

Nussbaum argues that a good human life is one that enjoys a high 'threshold' level of capability on each of the dimensions. Now, it is easy to be sympathetic to such a suggestion at the level of theory, but at the same time one might suspect that it dodges the hard public policy questions. For it may be that very few, if any, societies in human history have ever been able to offer their citizens a high level of sufficiency of each functioning. The question then arises of how a government should set its priorities in cases where it cannot bring every individual to satisfactory level of all capabilities. On this issue Nussbaum appears to be silent, yet from a policy point of view it is an essential question. Indeed it is, in a sense, the question that frames the enquiry as I have set it out above. 
In the project that led to the publication of Disadvantage, Avner de-Shalit and I arranged to test the capability approach by conducting some interviews with two groups of people who in their own ways are experts about disadvantage: those who work in social service provision, and those identified by such workers as disadvantaged. Prior to the interviews, we added a further three capabilities to Nussbaum's list:

11. Doing good to others: Being able to care for others as part of expressing your humanity. Being able to show gratitude.

12. Living in a law-abiding fashion: The possibility of being able to live within the law; not to being forced to break the law, cheat or to deceive other people or institutions.

13. Understanding the law: Having a general comprehension of the law, its demands, and the opportunities it offers to individuals. Not standing perplexed facing the legal system.

One part of the interview was to ask the interviewees whether there was anything else that we had missed. Several interviewees who either were asylum seekers, or worked with immigration services or in refugee camps, made suggestions which have led us to include:

14. Verbal independence: Being able to communicate in the dominant language for yourself.

At first we were surprised by this, but upon reflection we realised that interpretive services are no substitute for being able to make your own case for yourself, and being able to understand and respond to the nuances of any reply.

Now, there is room to question whether these additional categories overlap with, or even repeat, other capabilities that are already on the list. And there remains much future discussion to be had, among philosophers, policy makers, social workers, politicians, journalists and members of the public as to whether this is the best list of capabilities to use, given that it must meet the twin goals of being a reasonable account of human well-being, and can serve policy purposes of intersecting with possible sources of action and influence by government, and local government, agencies. But I will not pursue this here.

\section{Risk and Insecurity}

Rather than trying further to refine the account of functionings, I need, instead, to introduce one further element of the analysis, which is particularly important for its intersection with the social determinants of health. Many political philosophers have, of course, been ex- tremely interested in providing accounts of human wellbeing, and the expanded list of functionings just provided is only one of many such accounts. However, there has been a tendency to concentrate on what we might think of as the statics of well-being: how well a person is doing at any one time. Nevertheless, on further consideration it seems evident that my current well-being depends not only on my present states, but, as Hobbes emphasised, my current ability to secure future states of well-being. Hobbes's claim that human beings seek felicity-their present ability to satisfy their future desires-is an important insight, but one that has left relatively little trace in contemporary political philosophy (Hobbes, 1996; for an important exception, see Pogge, 2002).

In the analysis of Disadvantage, we attempted to incorporate the more dynamic idea that one's present wellbeing must make reference to future states by means of the notions of risk and insecurity or vulnerability. Our thesis, which we do not believe to be controversial, is that one person will be worse off than another if he or she is insecure in the sense of being unwillingly subject to risks that another is not. On this account, for example, someone who is living in rented accommodation knowing that the landlord has the right to terminate the contract on one month's notice is worse off than someone who has much greater security of tenancy, even if the costs and the accommodation are otherwise identical.

Hence, security, it seems clear, is valuable. The question, though, is why. Or to put it the other way round, what is so problematic about insecurity? In Disadvantage, we have provided an account of the impact that insecurity has on well-being, although it now seems to me possible to simplify that account. The degree to which insecurity is problematic can be explicated along (at least) the following dimensions:

(1) Vulnerability: The risk that the unwelcome event(s) will happen, in probabilistic terms.

(2) Control: The ease, difficulty or cost of reducing one's vulnerability.

(3) Resilience: The further consequences of the unwelcome event, and the ease, difficulty and cost of taking steps to reduce such consequences and returning towards a previous state.

(4) Anxiety: Concern about the risk of the feared event and the consequences of suffering further effects.

The first of these can be thought of as 'objective' to the degree that any future probability is regarded as objective. In the case of housing, for example, it may be that I can get a good idea of my vulnerability by understanding how landlords like my own have acted in the past. If it is very rare that landlords evict people at short notice, it may 
be reasonable to think my vulnerability is not too severe, although it may be that I know of special factors in my own case that will make a difference. In the case of health, for example, vulnerability can sometimes be estimated through standard epidemiology and knowledge of risk factors.

Control, and here especially protective control, is rather different. The thought is that one element of insecurity is the difficulty or cost of taking steps to reduce one's vulnerability. Perhaps in order to reduce vulnerability, one will have to pay a premium to one's landlord to improve security of tenure, or move to less convenient accommodation. Here, then, we can see that the element of control has two aspects. There will be those who find the cost of reducing their vulnerability too high, and throw themselves on the mercy of chance. They may well, then, as a result suffer the unwelcome event-eviction, illness - and this will be captured in whatever means are used to measure vulnerability. On the other hand, some may be able to take steps to reduce their vulnerability; although where this is difficult or costly, it will be likely to make them worse off in respect of their achievement or security in terms of other functionings. Paying more for housing will mean having less to spend on other things, moving further out of town might increase commuting time, and so on. In the case of health, purchasing more expensive, healthy foods, taking exercise and avoiding risky behaviour, all have costs, which can vary between individuals and social settings. Some of those who pay such costs will successfully reduce their vulnerability. Worst of all, of course, will be those who attempt to reduce their vulnerability by taking costly measures, but fail to achieve this. They will lose in both senses.

The third dimension was resilience. This is now a much used term, but in the present context refers to the further consequences of the unwelcome event happening, and the person's ability to recover from it, in terms of cost and difficulty. If one is evicted at short notice, how bad will it be? For a large family, with no social support network around them, it may be a disaster. For a young single person, with a highly supportive network, the consequences may be substantially mitigated. For those living in a society in which market-driven medicine is the norm, the cost of ensuring that falling ill does not lead to financial disaster may be very high, in terms of insurance policies, and even then there may be payout caps and other exclusions. And if one becomes ill, will that put other financial strains on one's family through loss of earnings, or does one's society have mechanisms in place to provide a cushion? Resilience, in this sense, is understood not as a trait of personality, but as a type of social fact, and one that can be affected by decisions one takes oneself, as well as policies adopted by national and local government.

Like control, resilience has two aspects. Those who fail to achieve resilience are likely to suffer. The unwelcome event will be likely to be more serious and more sustained than it would otherwise have been, and this will show up in increased vulnerability. And indeed, the unwelcome event may well bring others in its train. But those who do achieve resilience, while protecting themselves from vulnerability, will very often pay the cost in other ways, through increased financial expenses, effort, exhaustion and so forth (depending on what one is attempting to mitigate). ${ }^{1}$

Finally, anxiety concerning either the feared event, or its consequences, is another very common aspect of insecurity. Of course it is perfectly possible for those who face a severe threat of some sort not to have any great concerns about it. For example, they may be ignorant, or they may have a cheerful or optimistic character, or they may have some sort of 'motivated irrationality' to reduce dissonance. But very often people will be anxious about unwelcome events and their consequences. In this case the best way of removing anxiety is, of course, to reduce its source by reducing vulnerability or increasing resilience. Indeed the existence of anxiety may well lead people to take protective steps of this sort. But anxiety itself is one of the greatest harms suffered by those who find themselves vulnerable, in that it is persistent and does not depend on whether the feared event actually takes place.

Having set out the account of the manner in which insecurity can be problematic for an individual, we can now very easily see how the functionings laid out in the section 'Understanding Disadvantage' interact with one another in a number of ways.

In the first instance, there are some very direct causal connections. And, indeed, the theory of the social determinants of health helps establish this point. Those with poor social networks, and hence poor 'affiliation' in our terminology, will be more vulnerable with respect to their life expectancy and health. This is a simple, direct, causal relation, where doing poorly in one respect leads to vulnerability in another. There are many similar examples. Anyone who relies on their income to meet their basic daily needs will, of course, find that threats to earning an income are equally threats to meeting their daily needs.

There are, however, more subtle connections between functionings. For example, attempts to secure one functioning-in other words the cost of control, in the framework set out above-could often lead to increased vulnerability with respect to another. There are innumerable examples of people taking serious risks with their life 
and health in order to put food on the family table. Here such people put their obligations to members of their own families above their own health and safety. But there are many other real examples involving other functionings. Consider the example of rough sleepers who refuse to enter a homeless shelter on a cold winter's night if it means abandoning their dog overnight. Here a person is trying to secure his or her relation to a member of another species, and is prepared to increase vulnerability to his or her own life and health if that is the cost of doing so.

\section{The Least Advantaged}

Having set out a complex account of well-being in the previous sections, the question with which we begun returns with particular force. How is it possible to identify the least advantaged on such a view? Not only are there many dimensions of well-being, the dimensions themselves are all complex, both in terms of having subcategories within them, and in the further analysis of adding security to the account. Security itself is complex, and although this may add up to a plausible account of well-being, or at least of advantage and disadvantage, the task we set out of determining who is among the least advantaged in society seems daunting. It appears that it is necessary to measure performance in each category, and then to work out a weighting of different categories so that it is possible to decide who is better or worse off. Yet at the same time it seems that there is no natural, non-arbitrary, way of doing this.

Now, the task of measuring performance in each category of capability or functioning will be necessary whatever approach one takes, and much work is already ongoing in this respect. In some cases the matter is fairly simple - the capability of life is relatively easily measured by means of life expectancy, for example-whereas in others, such as the indicators of the capability of bodily health, matters are much more complex and contested. But let us assume that it is possible to come up with at least a rough account of how each person does in respect of each category of functioning, and consider the question of what we should now do in order to attempt to determine who is the worst off.

With the extensive account of functionings set out above, it seems a formidable task to try to determine who in society is worst off. However, one approach suggests that such a task is unnecessary. Rather than trying to determine who is worse off overall, a task that seems highly problematic, it may be possible to rest content with something else. After all, we have assumed that it is possible to provide a rough measure of how each per- son does in each category. If that is so, should it not be possible, therefore, simply to attend to the least advantaged in each dimension? Those with the poorest health should receive our attention, however well off they are in terms of affiliation, control over the environment, or other functionings. This is a version of what has been called the 'separate spheres' position (Walzer, 1983): in this case each person should be judged in terms of how they do in each category, and those towards the bottom in each category should receive priority in respect of that category. On such a view there is simply no need to come to an overall assessment of disadvantage and advantage.

There is much to be said in favour of this approach. It appears to respect the often held view that the categories of functioning are incommensurable with each other. Someone lacking in health cannot be compensated by the provision of greater control over their environment, and so on. There appear, therefore, to be good philosophical grounds for accepting the separate spheres argument. It also has the powerful advantage of allowing us to sidestep the problem of having to decide who are the least advantaged members of society.

There is, however, one very important problem with the separate spheres argument. It does not provide a perspective from which it is possible to judge how an overall government budget should be allocated. It provides an answer to the question of how a budget in a particular area should be spent-on the least advantaged in that area-but it does not provide any way of judging whether a government has got its priorities right in terms of its overall use of resources. Without an understanding of who the worst off are, and what are their most important problems, a government does not have a way of deciding whether to switch spending from one area to another. Consequently, it appears that there is no practical alternative to attempting to find a way of identifying the worst off overall. Hence the original problem with which we started remains as a challenge.

\section{Clustering of Disadvantage}

How difficult is it to come to an overall assessment of how well off or badly off individuals are, on the pluralist view set out here? In theory it appears very serious. Suppose that there were just two individuals, A and B, and two dimensions $\mathrm{x}$ and $\mathrm{y}$. If $\mathrm{A}$ does better than $\mathrm{B}$ on dimension $\mathrm{x}$ and $\mathrm{B}$ better than $\mathrm{A}$ on dimension $\mathrm{y}$, then which one does better overall depends crucially on how the achievements on the dimensions are valued against each other. But suppose it is also true that opinions both of experts, and of members of the public, differ as to how to value these achievements. Then it seems that there is 
disagreement over which of the two is the least advantaged. And if this can happen with two people and two dimensions, the problem is massively compounded for an entire population and 14 dimensions.

Yet we may fairly ask whether this argument overstates the difficulties. First we should note that the theory does not require a complete social ordering of all individuals or groups. Rather it needs to be able to identify those who are among the worst off in society. We are looking for what could be called a 'robust social ordering' at the bottom end of the ranking. This type of robust social ordering is a matter of the same people or groups showing up towards the bottom of the ranking even in the face of different assignment of values by different people engaged in weighing the different categories. So how could a robust social ordering of this type come about?

It appears that there are only two possibilities. One is that judges give very similar weightings to the different categories. If this is so, then they will obviously come up with very similar rankings of people and social groups in terms of advantage and disadvantage. The other possibility is that those who do badly in one respect will often tend to do in several others as well. Call this a 'clustering' of disadvantage. People who suffer from clustered disadvantage-multiple deprivation, in other words-will tend to be placed towards the bottom of the ranking, irrespective of how the different categories are ranked. Consequently, if it is true either that there is similarity of judgement, or clustering of disadvantage, then there will be a robust social ordering at least towards the bottom end of the scale, which of course is what we are most interested in.

Now, do we have any reason to believe that either 'similarity' or 'clustering' is the case? In fact we do. With respect to similarity-whether different people give similar weightings to different categories-it appears that to discover whether or not this is so would appear to require an extensive research project, and as far as we know that research has not been conducted. However, as mentioned above, as part of the research for the Disadvantage project, we conducted a number of qualitative interviews with 'experts' in disadvantage. One group of experts consisted of people in service provision of various sorts, such as volunteers working with asylum seekers, professionals in disability services or working with drug addicts, and so. Another group of experts, although a smaller part of our sample, were disadvantaged people themselves. Towards the end of each interview, after the various functionings had been discussed with the interviewer, we asked the interviewees what they believed to be the most important three functionings. Although there was not complete agreement, and a certain amount of interpretation proved to be necessary, six functionings came up much more often than any of the others. These were: Life; Bodily Health; Bodily Integrity; Sense, Imagination and Thought; Affiliation: and Control over one's Environment. Hence we can say that a certain degree of similarity in judgement has been observed, and further, after the book was completed, additional interviews were conducted, which tended to replicate the same results. However, although statistically this is too slender a basis on which to conclude that similarity in judgement holds generally, it nevertheless provides valuable information.

If we can rely on this result then it takes us half-way to the legitimate confidence that there is a robust social ordering. For if, as seems to be the case, these six functionings are generally believed to be more important than others, then in order to detect a robust social ordering we need only investigate whether there is clustering between these functionings. If it turns out that those who do badly on one of these six dimensions tend to do badly on others-or at least are at exceptional risk of doing badly on others-then it seems clear that those individuals or groups that suffer from a clustering of these most important functionings will be towards the bottom of the social ordering. And, by means of the evidence of the social determinants of health this is exactly what we will find. It appears, therefore, that our analysis of disadvantage and the social determinants of health are made for each other.

For consider the claims of Marmot concerning those factors that are likely to lead to increased risk of illness and early death (in our terminology: render the functionings of life and health insecure). Of course, part of the argument of this form of epidemiology is that single causes are not to be expected. Nevertheless, there are 'determinants' of health, or more strictly ill-health, which raise the probability of illness and early death. Among these are poor social networks (in our terminology 'poor affiliation'), low control over one's life (control over one's environment) and poor education (part of 'sense, imagination and thought'). Those who do badly in one or more of these will tend to do badly in terms of the secure functionings of health and life. And other studies show that risks to bodily integrity (fear of crime or assault) can lead people to take steps that can be greatly risky to their health. This, for example, is the theme of Klinenberg's Heat Wave, which showed that many of those who perished in the Chicago Heat Wave of 1995 did so because they had taken precautions against rising crime, such as staying at home and keeping their windows shut at night (Klinenberg, 2002). 
Hence we were able to use the thesis of the social determinants of health in order to argue that there is good reason to believe that important disadvantages tend to cluster, and so there is also good reason to believe that it is possible to identify a set of least advantaged groups, who suffer from the clustering of disadvantage. Such a claim is also supported by other evidence concerning multiple deprivation, but the particular usefulness to our project of especially Marmot's work is that partly as a result of the influence of Sen, he has tended to report his findings in categories that are much more sympathetic to the capability approach than other social researchers have done to date.

We suggest, then, that the theory of the social determinants of health provides good reason to believe that disadvantages in the most important categories of functioning cluster together. But suppose we are wrong. Suppose it is not the case that disadvantage clusters in the manner outlined. Does this show that our project is a failure? We would draw a different conclusion: that to some degree the project is unnecessary, for, if the evidence shows no clustering of disadvantage, then there is no least advantaged group in society. Or, to put it slightly differently, if there is no clustering of disadvantage then who one thinks of as least advantaged will depend on what one thinks is most important, and this may shift from person to person. If disadvantage does not cluster then there is less for social policy to do than we had imagined.

This, in turn, suggests a policy goal: the declustering of disadvantage. A society in which disadvantage is declustered is one in which the goal of giving priority to the worst off does not give clear guidance, as, in a sense, there is no group of the worst off. To that degree, such a society has achieved some measure of equality. Accordingly, those who want to give priority to the worst off have every reason to be interested in the project of declustering disadvantage, for, in effect, to do so is to abolish the category of the least advantaged. We can, for example, contrast the declustering approach to the maximin approach advocated for by Rawls and others (Rawls, 1971). Maximin suggests that the worst off should be made as well off as possible. This is consistent with the existence of inequality, and, indeed, with ever larger inequalities. The declustering disadvantage approach advocates transcending the idea of a least advantaged group. Once disadvantage is declustered then there is no (obviously) least advantaged group (although it may still be true that some do especially poorly in one dimension and require urgent attention in this respect, even if they do not suffer from clustering of disadvantage).
How, though, is disadvantage to be declustered? Clearly one needs to be careful with policy recommendations here. Formally, disadvantage can be declustered by damaging the lives of those who are doing well in some dimensions. Although it would be wrong to suppose that equality can generally be achieved without anyone ever suffering a loss, still, ideally, disadvantage should be declustered, as far as possible, by finding ways of improving the lives of those at the bottom, rather than destroying the lives of those at the top. Hence both a relative and an absolute dimension are necessary to avoid declustering the wrong way.

But still, this does not show how disadvantage could be declustered. Here we need to appeal to social science, to consider what instruments are at our disposal. In particular we need to know how the different functionings relate to one another in causal terms to know whether a form of action will simply replace one disadvantage with another, or will actually do overall good. So, for example, some policies of rehousing make people better off in terms of improved shelter and therefore bodily health, but at the same time destroy communities and reduce affiliation, which for some people will have other effects too. Whether the total effect is positive or negative will vary from case to case, but it is possible that very substantial harm could be done through a misguided and expensive attempt to do good.

Accordingly, as part of the Disadvantage project, we introduced two concepts in order to help us think about possible interventions. These are 'corrosive disadvantages' and 'fertile functionings'. A corrosive disadvantage is a disadvantage that is likely to compound disadvantage. So, for example, drug or alcohol addiction is very likely to have a wide range of negative effects on an individual's life. A fertile functioning is something the possession of which is likely to have positive effects elsewhere. Now, it may seem that corrosive disadvantages and fertile functionings are simply different ways of referring to the same thing: if the presence of something is bad for you in various ways, its absence must be good. Now while, in a sense, this must be true, it is important that such a view is not applied naively in social policy. For when harm has been done, it does not follow that the cure for the harm is taking away its cause. The point has been made very graphically with the example of running over someone with a steamroller. The cure, clearly, is not to reverse back over them. More generally, when something is 'broken', the cure very often needs to be found elsewhere than in reversing its cause.

This should not be a controversial point, but it does make social policy extremely difficult. Consider the application of epidemiology. The first task of epidemiology 
is to find statistically significant, non-accidental, correlations. The second step is to try to establish that there is some sort of causal relation between the variables. The third step, which is often highly contested, is to be able to establish cause and effect. So, for example, patterns correlating smoking to lung cancer were interpreted as the result of some sort of causal relation and then, later on, it was established beyond reasonable doubt that smoking causes lung cancer. Knowing this much helps us to understand how to reduce the probability of lung cancer: don't smoke. So it is very useful as a contribution to preventative medicine. But it tells us very little, if anything, about how to restore to health those who have lung cancer. In our terms, then, smoking is corrosive-almost literally_but the absence of smoking is not fertile, in that it does not spread good effects elsewhere.

These comments are, of course, relevant to the social determinants of health. Suppose it has been shown that unequal incomes increase ill health and reduce life expectancy for all. This would be a very good reason to caution a society currently experiencing income equality and good health against economic reforms that will bring about income inequality. But it doesn't follow from this that a society of income inequality and poor health can be brought to greater health by greater income equality. That might be like trying to cure the victim of the steamroller by reversing back again, or curing lung cancer by telling people to stop smoking. Conversely, it might be correct, and increasing equality may well improve health. The point is only that we do not know this even from studies that establish a causal link. Consequently a different sort of evidence is needed about effective social policy, and if we act without that evidence, we may find we do as much — perhaps more- harm than good, but without understanding why.

\section{Conclusion}

The main purpose of this paper has been to provide a summary of a research project in which the idea of the social determinants of health was used as an integral part of the analysis of disadvantage. The social determinants of health provide important evidence that many of the important functionings cluster together, especially at the lower end, and that we can expect those with vulnerability to poor affiliation, poor control over their environment, poor education and poor bodily integrity also to have vulnerability to poor health and life expectancy. This is an important connection between political philosophy and epidemiology, and a rather unusual one. But as always, it leaves a great deal still to be done.

\section{Note}

1. It is worth noting that those who improve resilience through the establishment of a supportive social network may find that not only does this not involve any significant costs, it also brings other benefits, both intrinsically and instrumentally.

\section{Acknowledgements}

This paper was written as part of the UCL Ethics of Risk project, sponsored by the Arts and Humanities Research Council, and I am very pleased to acknowledge the AHRC's support. It was presented at the launch conference of the UCL Centre for Philosophy, Justice and Health, and I am very grateful to the participants for their comments and to James Wilson and the editors of this journal for their very helpful written comments. This work was funded by Arts and Humanities Research Council, Ethics of Risk project.

\section{References}

Alkire, Sabina. (2002). Valuing Freedoms. Oxford: Oxford University Press.

Arneson R. (1989). Equality and Equal Opportunity for Welfare. Philosophical Studies, 56, 77-93.

Barry, Brian. (2005). Why Social Justice Matters. Oxford: Polity.

Brock, Gillian (ed.). (1998). Necessary Goods: Our Responsibilities to Meet Others' Needs. Lanham, NJ: Rowman and Littlefield.

Daniels, Norman. (2008). Just Health. Cambridge: Cambridge University Press.

Hobbes, Thomas. (1996). Leviathan. 1651. Cambridge: Cambridge University Press.

Klinenberg, Eric. (2002). Heat Wave: A Social Autopsy of Disaster in Chicago. Chicago: University of Chicago Press.

Marmot, Michael. (2004). Status Syndrome: How Your Social Standing Directly Affects Your Health and Life Expectancy. London: Bloomsbury.

Nussbaum, Martha. (2000). Women and Human Development. Cambridge: Cambridge University Press.

Parfit, Derek. (1998). Equality and Priority. In Mason, Andrew (ed.), Ideals of Equality. Oxford: Blackwell.

Pogge, Thomas. (2002). World Poverty and Human Rights. Cambridge: Cambridge University Press.

Rawls, John. (1999). A Theory of Justice. 1971. Oxford: Oxford University Press. 
Sen, Amartya. (1980). Equality of What? In McMurrin, S. M. (ed.), The Tanner Lectures on Human Values. Cambridge: Cambridge University Press, pp. 195-220.

Sen, Amartya. (1992). Inequality Re-examined. Cambridge MA: Harvard University Press.

Sen, Amartya. (1997). On Economic Equality, expanded edition. Oxford: Clarendon Press.
Walzer, Michael. (1983). Spheres of Justice. Oxford: Blackwell.

Wilkinson, R. (1996). Unhealthy Societies: The Afflictions of Inequality. London: Routledge.

Wolff, Jonathan and de-Shalit, Avner. (2007). Disadvantage. Oxford: Oxford University Press. 